\title{
Dye Electropolymerization for Electrochemical Analysis. A Brief Review
}

\author{
Volodymyr V. Tkach 1,*iD, José Inácio Ferrão de Paiva Martins ${ }^{2}$ (D), Yana G. Ivanushko ${ }^{3}$ (D) Petro I. \\ Yagodynets $^{-1}$ (i) \\ Chernivtsi National University, 58001, Kotsyubynsky Str. 3, Chernivtsi, Ukraine \\ Faculdade de Engenharia da Universidade do Porto, 4200-465, Rua Dr. Roberto Frias, s/n, Porto, Portugal \\ 3 Bukovinian State Medical University, 58001, Teatralna Sq. 9, Chernivtsi, Ukraine \\ * Correspondence: nightwatcher2401@gmail.com(V.V.T.);
}

Scopus Author ID 55758299100

Received: 20.06.2021; Revised: 15.07.2021; Accepted: 18.07.2021; Published: 13.08.2021

\begin{abstract}
Conducting polymers are among the most used organic materials so far. Their use as electrode modifiers in electroanalysis includes the active intervention in the electroanalytical process, like electrochemical transfer mediation, which increases the affinity between the electrode and the analyte. The conjugated dyes are one of the most popular monomers for electrochemical polymerization. This work brings a brief review of the dye electropolymerization technique and the use of dye polymeric coatings in electrochemical sensing.
\end{abstract}

Keywords: electrochemical sensor; chemically modified electrodes; conjugated dyes; conducting polymers; electropolymerization;

(C) 2021 by the authors. This article is an open-access article distributed under the terms and conditions of the Creative Commons Attribution (CC BY) license (https://creativecommons.org/licenses/by/4.0/).

\section{Introduction}

Conducting polymers are one of the most used organic materials during the last five decades [1 - 8]. Possessing the prolonged conjugated double-bond system (which may be aromatic or not) and being capable of combining the properties of plastics and metals with the facility of modification, it is widely used in corrosion protection, capacitor systems, transductors, OLEDs, energy conversion, and electroanalytic [9-15].

Generally, the most used conducting polymers are based on small monomer molecules like pyrrole [16 - 20], thiophene [21 - 25], aniline [26 - 32]. These monomers are relatively cheap and easy to polymerize in chemical or electrochemical ways on metallic and carbon electrodes. Nevertheless, like common organic dyes, the larger molecules may also be used as a monomer for electropolymerization [33 - 119].

In this paper, a brief review of electropolymerization of conjugated dye molecules is given in order to systematize the information concerning dye polymers and their use in sensing, known by far.

\section{General statements on electropolymerization mechanism}

The electropolymerization of the conjugated compounds is usually given by a cationradical mechanism, considering the main Díaz path, modified by the Kim mechanism [1 - 32]. 
In the first stage, the monomer loses an electron, being thereby transformed into the cationradical (1):

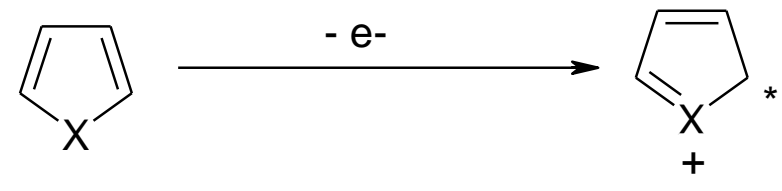

where $\mathrm{X}=\mathrm{CH}=\mathrm{CH}, \mathrm{CH}=\mathrm{N}$ (or other pnictogen element), $\mathrm{NH}$ (rarely, other pnictogen analogous group), chalcogen atom (generally $\mathrm{O}, \mathrm{S}$, more rarely $\mathrm{Se}, \mathrm{Te}$ ).

By this, the cation-radical may interact (2) with another cation-radical (classical Díaz interaction):

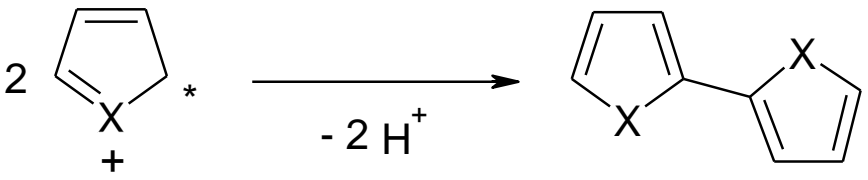

or with a non-oxidized monomer molecule by the electrophylic aromatic (3) substitution mechanism (Kim interaction):
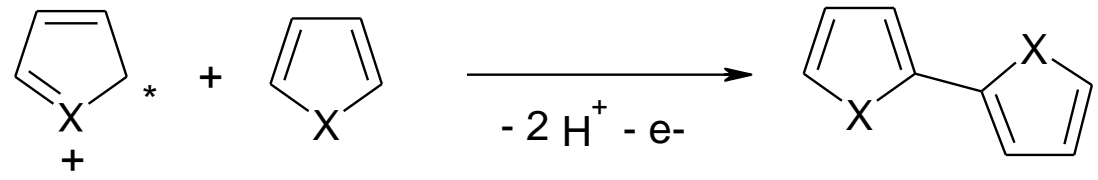

Either way, the dimer is formed. Its oxidation also yields the cation-radical, which grows by the same path as in $(1-3)$, yielding oligo- and polymeric molecules. The electropolymerization yields the conducting polymer in the doped form, in which the dopant counter-ions compensate the cationic centers. The dopant is generally removed by polarization change, reducing the polymer conductivity.

As for the polymerization over a carbon-based electrode, the grafting scenario, including the bonding between the carbon surface and the resulting polymer, is also foreseen and experimentally observed in [1 - 49]. The mechanism $(1-3)$ is valid for the direct electrochemical polymerization of different conjugated aromatic monomers, including the fused and condensed rings.

As for dyes electropolymerization and copolymerization [35 - 119], it is generally realized for electroanalytical and energy-conversion purposes over carbon materials. Their polymerization potential and the electroanalytical affinity of their polymers will strongly depend on their chemical composition. It is known that, generally, the polymerization potential of aromatic molecules possessing donating groups is lower, and of those possessing accepting groups is higher [1 - 34]. Also, considering that the majority of dye polymers assist proton transference in electroanalytic, their efficacy for this purpose will be different.

In this work, the electropolymerization of three major dye classes (triphenylmethanes, azo-dyes, and condensed aromatic dyes) for electroanalytical purposes will be briefly reviewed, described, and approached.

\section{Results and Discussion}




\subsection{The electropolymerization and sensing application of the triphenylmethane dyes.}

Triphenylmethane dyes are one of the most known dye classes. They consist of one of the oldest known extremely brilliant and intensively colored dyes. The oldest known (1859) triphenylmethane dye is fuchsine basic (Figure 1)

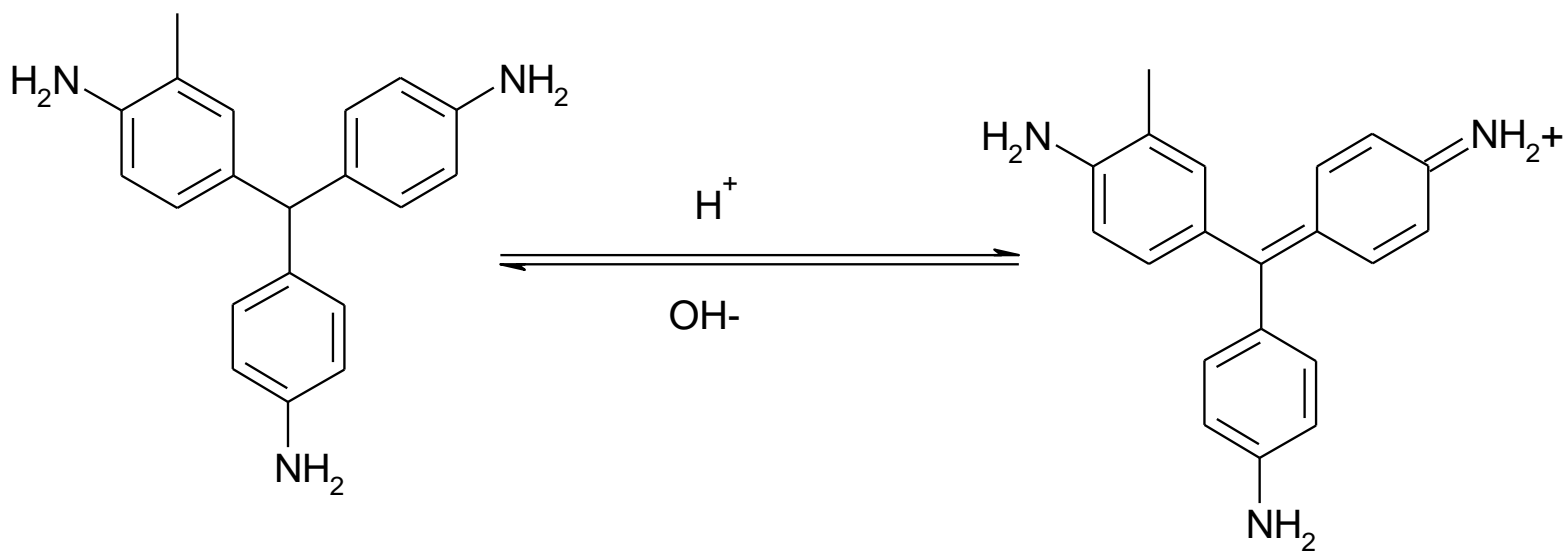

Figure 1. Fuchsine basic leukoform (left side) and colored form (right side).

Fuchsine basic dye has been electropolymerized [35] over a glassy carbon electrode (GCE). Considering the dye composition, the polymerization mechanism and the aminogroup sensitivity to the solution $\mathrm{pH}$, the polymerization kinetics has been shown as highly dependent on the background electrolyte composition and buffer used for this purpose. This is linked to the different properties of the unprotonated (donor) and protonated (acceptor) amino group, like also their ability to form the most efficient polymer molecule.

The reason why poly (FB)-modified electrode is efficient for the dopamine electrooxidation at neutral $\mathrm{pH}$ is that both the proton transference from dopamine and the dye polymer mediation is more efficient in the neutral medium due to the dopamine hydroquinonequinonic oxidation mechanism and the possibility of both forms to coexist in neutral medium.<smiles>CC=Cc1ccc(C(=C2C=CC(=[NH2+])C([S-])=C2)c2ccc(N)c([S+](=O)([O-])[O-])c2)cc1C</smiles>

Figure 2. Fuchsine acid non-ionic (left side) and zwitterionic form (right side).

As for fuchsine acid dye (Figure 2), it has also been polymerized in [36]. Contrarily to the fuchsine basic, fuchsine acid dye is harder to oxidize due to the presence of three highly accepting sulfonic groups. Nevertheless, it is capable of forming the so-called self-doped conducting polymers, like also to be used as a dopant in the electropolymerization of another molecule

In [36], the poly(fuchsine acid) modified electrode has been used to simultaneously determine ascorbic acid, adrenaline, and uric acid. The proton-transfer rate of each of three of 
the mentioned compounds with poly(fuchsine acid) is different, which explains the peak separation of each of the three mentioned compounds.

One of the most known triphenylmethane dyes is malachite green (Figure 3). It has been electropolymerized in [37] in the potentiodynamic mode in different solutions. The polymerization mechanism involved the partial quinonization of the dye molecule. A Schiff moiety appeared in the polymer molecule, which gave the polymer a high affinity to proton transference. Therefore, the sensor described in [37] has provided a high catalytic activity for the simultaneous determination of dopamine and ascorbic acid.

The same dye has been polymerized in [38] to be used to determine tetracycline antibiotics by adsorptive stripping voltammetry on GCE. Taking into account the similar electrooxidation mechanism of the compounds detected in [37] and [38], the two-steps irreversible electrooxidation of tetracycline has been easily realized at a mildly alkaline $\mathrm{pH}$, closer to neutral. The sensor may provide efficient tetracycline electrochemical determination in biological liquids and pharmaceutical formulations.

The same polymer has been obtained in the same manner over the graphene sheets to determinate the methylparathione pesticide [39] simultaneously, alongside its alkaline hydrolysis product. The graphene nanosheets increased the stability of poly(malachite green), which enhanced the catalytic activity of the dye polymer and gave the synergic effect to the composite properties.
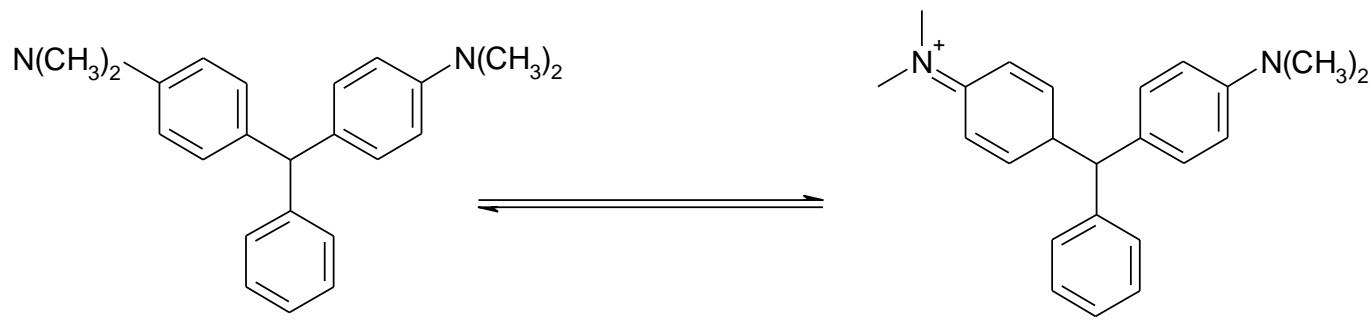

Figure 3. Malachite green non-ionic (left side) and ionic form (right side).

A similar dye - brilliant green (Figure 4) has been electropolymerized on carbon nanotubes to host the enzymes, capable of detecting glucose and ethanol selectively in beverages [40]. Moreover, the capability of PBG/CNT composite in enzyme hosting has been thereby compared with that of PEDOT/CNT composite, and the efficiency of the dye-based polymer has been confirmed to be better. The PBG/CNT composite has shown the highlyenhanced sensitivity for glucose and ethanol determination, by glucose oxidase and alcohol dehydrogenase entrapment.
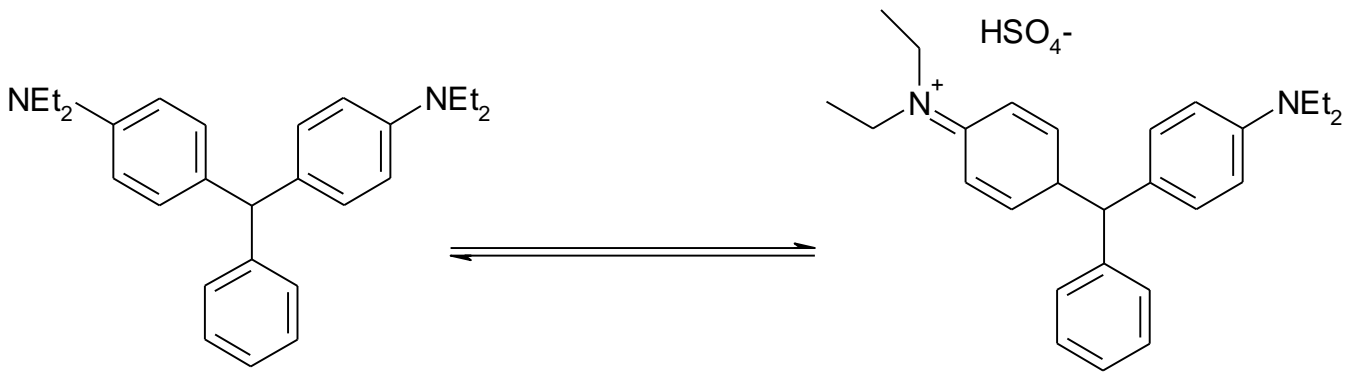

Figure 4. Brilliant green non-ionic (left side) and ionic form (right side).

Also, in [41, 42], the same dye has been polymerized and used for the different analytes. The film has shown excellent selectivity for the peak separation due to the different affinity to each of the mentioned analytes. Chrystal violet (Figure 5) has been electropolymerized for 
electroanalytical purposes several times. For example, in [43], this dye has been electropolymerized over GCE, providing the efficient determination of three biphenolic isomers with the nanomolar $(80 \mathrm{nmol})$ detection limit. Moreover, the differences in oxidation mechanism of each of the analytes provide the peak separation of the isomeric biphenolic compounds is between 100 and $430 \mathrm{mV}$, which lets the selective determination of both of them.
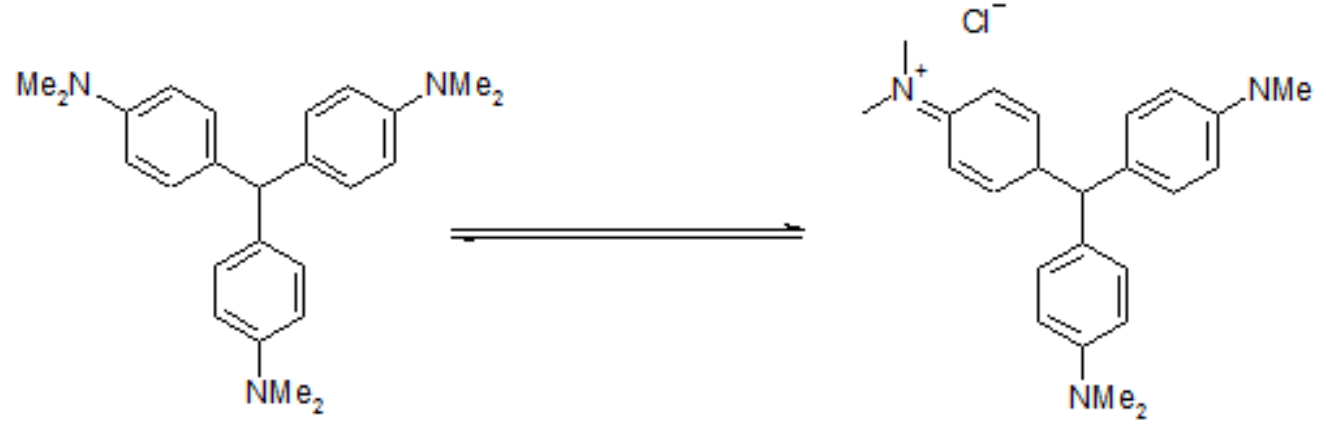

Figure 5. Chrystal violet non-ionic (left side) and ionic form (right side).

In [44], the same dye was polymerized on the surface of the pencil graphite electrode. The polymer showed an excellent electrocatalytic activity towards the determination of $\alpha$ - and $\gamma$-hydroquinones with nanomolar detection limits for each one, being the limit for $\alpha$ hydroquinone lower. As in the previous works, either the polymerization process or the electroanalytical potential depended on the solution composition, and the working $\mathrm{pH}$ for the most efficient electrochemical behavior was observed as close to neutral.

In [45], Phenol red dye (Figure 6) has been electropolymerized over the reduced graphene oxide-modified GCE. It has shown high selectivity towards the ciprofloxacin at $\mathrm{pH}=5$,5. It's important to mention that the mildly acidic solution $\mathrm{pH}$ is introduced to neutralize the mild ciprofloxacin basicity in order to enhance the proton transfer rate of phenol red dye. Also, the ciprofloxacin molecule interacts with the sulfogroups of the proper dye. By this, the detection limit of ciprofloxacin becomes 2 nmol.

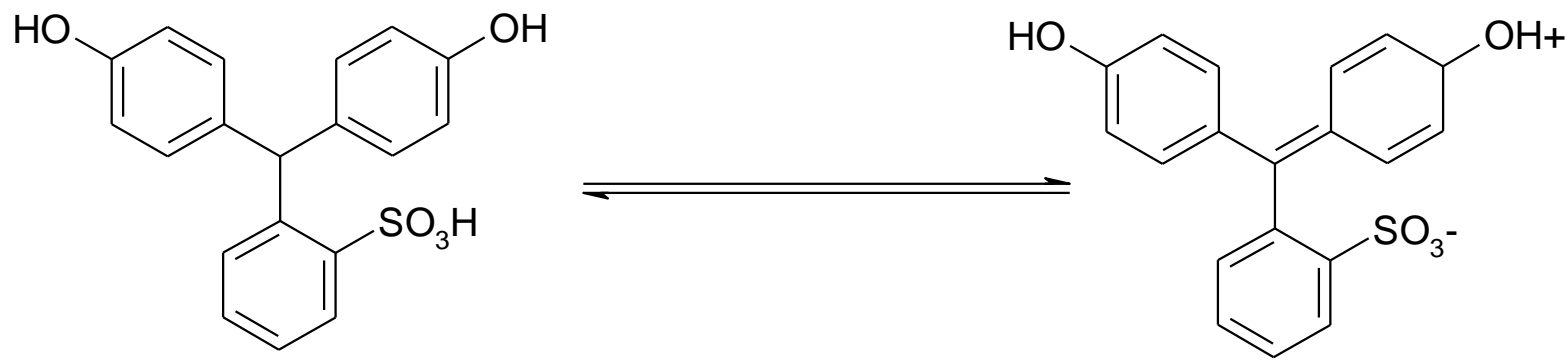

Figure 6. Phenol red leukoform and ionized form.

Sometimes the dye polymers may be used in the overoxidized form. Although they generally become less conducting, their sensitivity towards some compounds like metal ions may enhance [46]. In work [47], poly(phenol red) polymer has been obtained and overoxidized over the GCE. The polymer overoxidation was used to determine the trivalent antimonium ion in $0,0075 \mu \mathrm{g} / \mathrm{l}$ detection limit. The selectivity was based on the complex formation of overoxidized dye polymer with antimonium. The non-overoxidized polymer may also be used for the electroanalytical determination of metallic cations. For example, in [48], it was used to detect the bivalent lead with the detection limit down to $2 \mathrm{nmol} / \mathrm{l}$. 
So, the triphenylmethane dye polymers may be efficient electrode modifiers for the electrochemical determination of different compounds. The working $\mathrm{pH}$ and detection limit will depend on the dye and analyte composition and state (normal or overoxidized polymer), like the interaction mechanism.

\subsection{Synthesis and electroanalytical application of azo dyes polymers.}

Azo-dyes are one of the most used classes of dyeing compounds with both aryl and hetaryl moieties. Also, they are interesting objects of the electrochemical analysis [49-60], being the Sudan family (Figure 7) one of the most used.<smiles>Oc1ccc2ccccc2c1/N=N/c1ccccc1</smiles>

Figure 7. Sudan I dye.

Despite the high electropolymerization potential, both azo-dyes and their polymers clearly differ in electrochemical response to proton-leaving electroanalytical oxidation processes due to highly accepting azoic moiety. Also, hydroxyl groups or pyridine nitrogen atoms in ortho-position to the azoic group permit efficient metal complex formation [61, 62].

In the works [63, 64], the Sunset yellow azo-dye (Figure8) has been electropolymerized by cyclic voltammetry on CPE. In work [63], an excellent electrocatalytic activity has been verified for poly(Sunset yellow)-assisted determination of dopamine, ascorbic acid, and uric acid. The sensor permits the determination of the mentioned compounds at physiological $\mathrm{pH}$ $(7,4)$, and the proton transfer is realized via the azoic group with its further electrochemical regeneration.<smiles></smiles>

Figure 8. Sunset Yellow dye.

In [65], the same dye was polymerized in order to determinate the chlorogenic and ferulic acid, hydroquinonic compounds with a similar structure to dopamine. The electropolymerization was carried out on the glassy carbon electrode at the $1,1 \mathrm{~V}$ potential for 
30 seconds. The sensor was applied to determine the mentioned acids in coffee in micro- and nanomolar concentrations, providing an efficient diffusion-controlled system.

In [66], the Sudan III (Figure 9) has been electrochemically polymerized on CPE by cyclic voltammetry. The resulting polymer has shown high dopamine, ascorbic acid, and uric acid activity, separating their oxidation potentials. Sudan III has implusioned catalytic activity and polymerization capability, as it possesses two azoic fragments and a longer conjugated system. Nevertheless, due to the accepting properties of the azoic group, its polymerization potential remains relatively high.

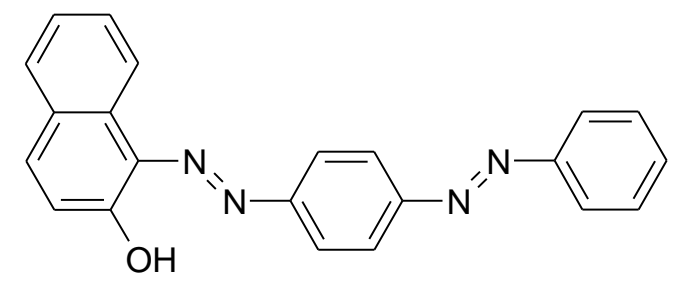

Figure 9. Sudan III dye.

In the works [67] and [68], Congo red dye (Figure 10) has been polymerized for the determination of dopamine and terazosin correspondently. In both of the cases, the polymerization was given on the carbon material by cycling the anode potential between $-0,2$ and $+1,5 \mathrm{~V}$ in a slightly alkaline medium. In work [67], dopamine was successfully determined in the presence of ascorbic and uric acids, providing an efficient electrode response in relation to the bear carbon electrode. The same effect was achieved for terazosin [68]. Both of the electroanalytical processes have been realized in neutral $\mathrm{pH}$.

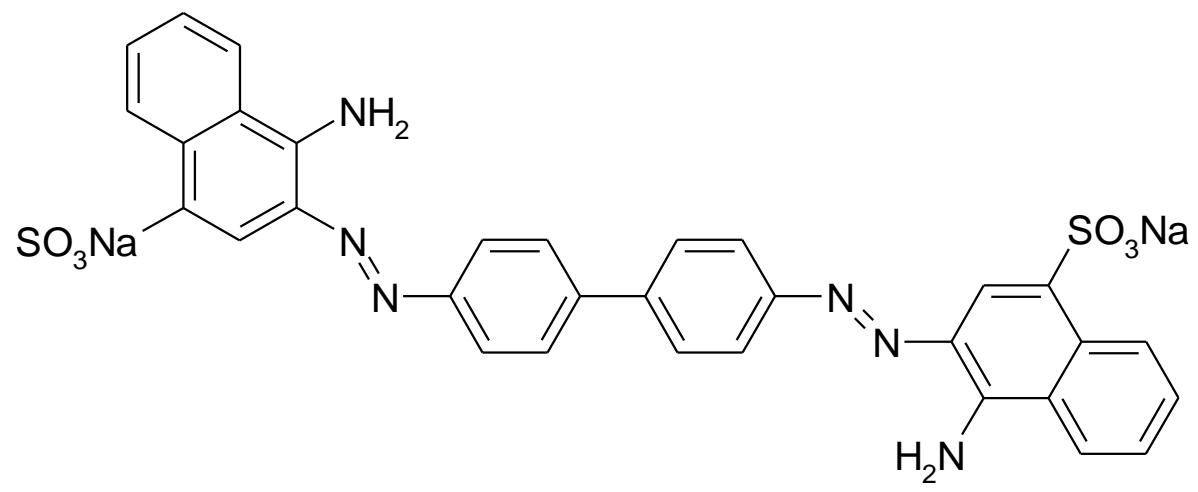

Figure 10. Congo Red dye.

Methyl orange dye (Figure 11), frequently used as a $\mathrm{pH}$ indicator, has been polymerized on carbon materials. In [69], its polymer has been used for the 4-nitrophenol determination with the detection limit of $170 \mathrm{nmol}$. Methyl orange dye has exhibited an oxidation peak at $0,93 \mathrm{~V}$, and the background current was higher than the bare GCE.

Yet, in [70], the same dye was electropolymerized at a potential range from $-0,6$ to 1,4 $\mathrm{V}$ on CPE. It was used to detect vanillin at mildly acidic $\mathrm{pH}$, in which the phenol ether group was first hydrolyzed and further oxidized to the correspondent quinonic form, providing the efficient determination of vanilin micromolar concentrations. The electrochemical effect of the method was reinforced by hydrogen bonding between the vanillin molecule and the polymer. 


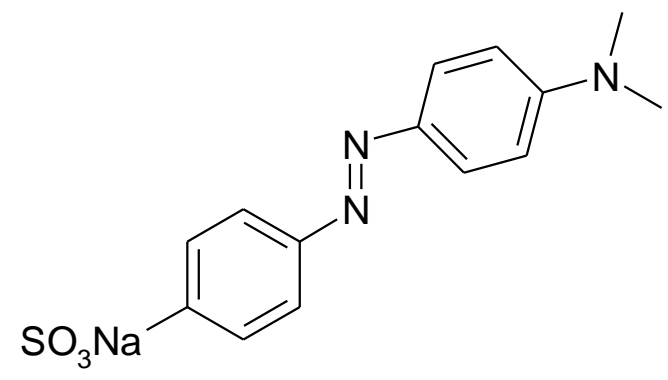

Figure 11. Methyl orange dye.

In [71], the same dye was polymerized on MWCNT to detect the amodiaquine drug at micromolar concentrations with a detection limit of $89 \mathrm{nmol}$. It was ready to use for drug determination in pharmaceutical formulations and human urine samples.

In work [72], acid red 176 azo-dye (Figure 12) has been polymerized in order to yield a conducting polymer coating sensitive to dopamine and uric acid in the presence of ascorbic acid. The film was prepared on a glassy carbon electrode and has exhibited the electroanalytic activity towards the oxidation of dopamine and uric acid in the presence of ascorbic acid at mildly acidic $\mathrm{pH}$. Moreover, it was capable of suppressing the ascorbic acid interferences, which made it an efficient electrode modifier for dopamine determination.

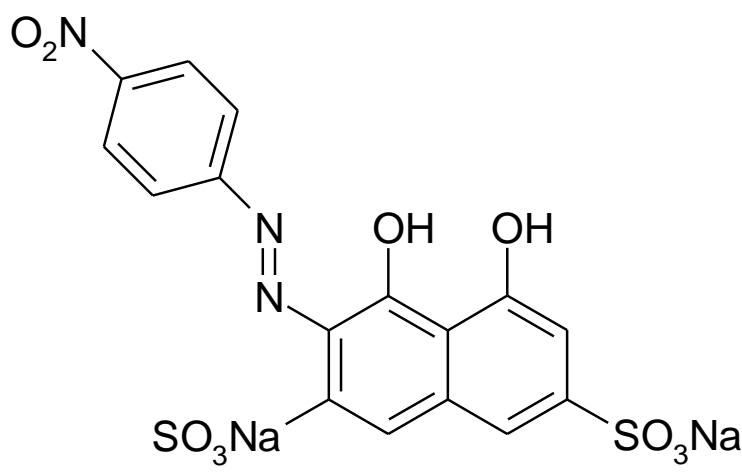

Figure 12. Acid Red 176 dye.

The work [73] is dedicated to the use of Evans blue dye (Figure 13)polymer for catechol and hydroquinone and catechol determination at mildly alkaline $(7,4) \mathrm{pH}$. The polymerization is realized at $\mathrm{pH}=7,4$ by $\mathrm{CV}$ scanning at potentials from $-0,6$ to $+1,6 \mathrm{~V}$. The detection limit for both hydroquinonic compounds was realized on micromolar ( 2 to $2,1 \mu \mathrm{mol}$ ) level, providing an efficient peak separation.<smiles>Cc1cc(-c2ccc(N=Nc3ccc4c(S(=O)(=O)O)cc(S(=O)(=O)O)c(N)c4c3O)c(C)c2)ccc1N=Nc1cc(O)c2c(N)c(S(=O)(=O)O)cc(S(=O)(=O)O)c2c1</smiles>

Figure 13. Evans blue dye. 
The mildly basic medium, in this case, favors the neutralization of the dye sulfoacid groups, which, while protonated, may impede the proton transfer.

In [74], the same dye polymer has been used to provide the electrochemical determination of riboflavin. The polymerization was given at graphite paste electrode with potential ranges from 0 to $1,4 \mathrm{~V}$, providing an efficient riboflavin determination at micromolar concentrations.

In work [75], eriochrome black $\mathrm{T}$ azo-dye (Figure 14) has been successfully polymerized on CPE for methdilazine determination. The polymerization process was given by $\mathrm{CV}$ between 0,0 and $1,2 \mathrm{~V}$, and the low-molecular dye oxidation subproduct also participated in the electropolymerization. The methdilazine determination was given most efficiently at $\mathrm{pH} 9,2$, in which eriochrome $\mathrm{T}$ is present in the salt form, and methidilazine is more easily deprotonated.

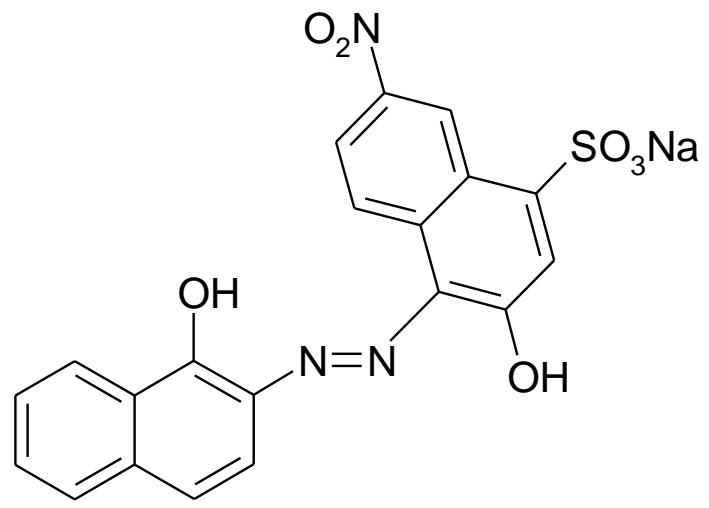

Figure 14. Eriochrome Black T.

In work [76], the same dye was electropolymerized on reduced graphene oxide. The gold nanoparticles were deposited over the dye polymer to enhance the electroanalytical effect towards the ascorbic acid, dopamine, and uric acid. The synergetic effect of the hybrid material components let the electrode lower the detection limit to nanomolar values in Vitamin C tablets and urine samples.

So, the azo-dyes may be efficiently electropolymerized over the carbon materials to provide the efficient electrochemical determination of biologically active compounds on micro and nanomolar concentrations. The electropolymerization is generally given by cyclic voltammetry cycling the potential between slightly negative to relatively positive $(0,8 \mathrm{~V}$ $\left.<\mathrm{U}_{\mathrm{p}}<1,8\right)$, due to the presence of accepting groups on the dye molecules. Also, the peak separation of different analytes for simultaneous detection is explained by the difference in the interaction of different molecules with the dye, mediating the proton and electron transfer differently.

\subsection{The electropolymerization and sensing application of the electropolymerized condensed} aromatic dyes.

The condensed aromatic dyes are polymerized even more often than the triphenylmethyl and azo-dyes because their long conjugated system allied to the great variety of functional groups capable of reacting with different analytes [77 - 119]. In the third section, a brief review of their activity towards the different sorts of analytes will be given.

In the works [77 - 79], the acridine orange dye (Figure 15) has been polymerized electrochemically on carbon materials, being guaifenesin (at $\mathrm{pH}=7)$, amoxicillin $($ at $\mathrm{pH}=5$ ), 
rutin (at $\mathrm{pH}=2$ in the presence of an ionic liquid). In general, the acridine orange polymerization is given by cyclic voltammetry between $-1,5$ and $+1,5 \mathrm{~V}$, providing an efficient polymer deposition. The high dye oxidation potential is explained by the presence of the highly accepting pyridinic nitrogen atom in the acridine molecule. On the other hand, the donating effect of the dimethylamino groups augments the electrophylic potential on positions 2 and 7 of the acridine ring, and they participate in electropolymerization.<smiles>Cc1ccc2cc3ccc(N(C)C)cc3nc2c1</smiles>

Figure 15. Acridine orange.

Yet, the $\mathrm{pH}$ change of the solution is explained by the necessity of neutralization of basic properties of the substituted acridine ring and(or) the analytes.

In work [80], acridine red dye (Figure16) was used to quantify dopamine in micromolar quantities. The acridine red electropolymerization was carried out by $\mathrm{CV}$ from $-1,0$ to $+2,5 \mathrm{~V}$, as the positively charged nitrogen atom, bound to the aromatic ring or oxygen heteroatom in another form, is a strong acceptor.

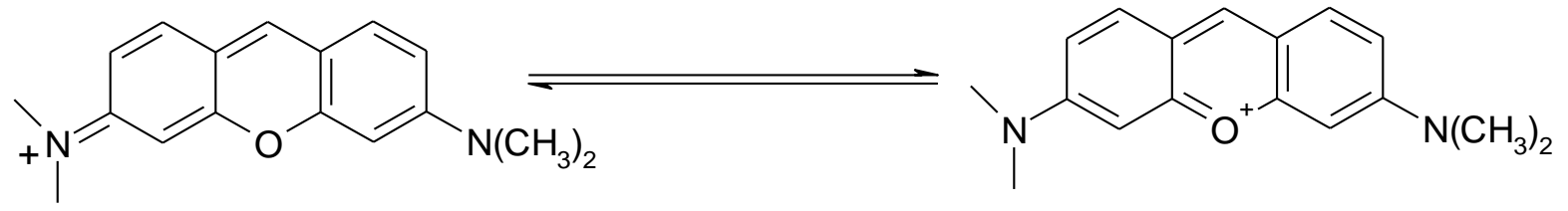

Figure 16. Acridine red in two resonance forms.

Acridine red dye is polymerized in more rigid conditions than acridine orange. Nevertheless, the electroanalytical response of acridine red dye towards the dopamine is enhanced, as dopaquinone and leukodopachrome and dopachrome products are formed, which may indicate the possible polymerization-initiated possibility of the dye.

Nile blue dye (Figure 17) is frequently electropolymerized in order to obtain the electroanalytical sensitivity to carbon materials [81 -83].

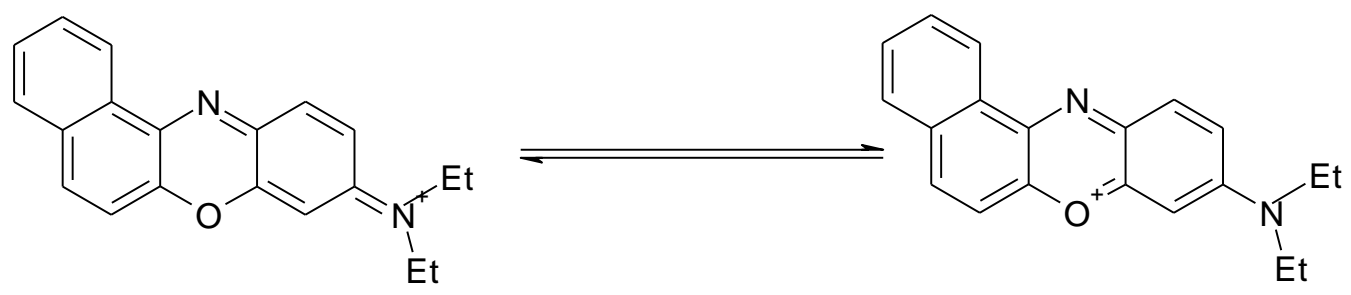

Figure 17. Nile blue in two differently charged forms.

Nile blue polymer was used to electroanalytical quantify ephedrine [81], paracetamol, tramadol, and caffeine [82], and a great variety of different biologically active molecules [83]. The electroanalytical process was given in neutral $[82,83]$ or mildly acidic $[81,82] \mathrm{pH}$, depending on the molecule analyzed. The electropolymerization was carried out at the potential between $-0,8$ and $+1,2 \mathrm{~V}$ in alkaline media, capable of catching out the protons, leaving during the electropolymerization. Also, in the alkaline media, the dye molecule becomes less accepting, being transformed into the form in Figure 18, which becomes easily polymerized. 
<smiles>CCN(CC)C1=CC2Oc3ccc4ccccc4c3N=C2C=C1</smiles>

Figure 18. Nile blue basic form.

Safranine dye (Figure 19) polymerization has been frequently used nowadays in order to enhance the electroanalytical sensitivity of carbon electrodes [84-88].<smiles>Cc1cc2nc3cc(C)c(N)cc3[n+](-c3ccccc3)c2cc1N</smiles>

Figure 19.bSafranine.

A great variety of the analytes have been detected by poly(safranine) modified carbon electrodes, including parathion [84], epinephrine and uric acid [85], 4-nitrophenol [86], rutin [87], and caffeine [88]. Due to the presence of two highly accepting nitrogen heteroatoms, safranin polymerization potential is foreseen to be high, the reason why the potential range between $-1,6$ and $+2,0 \mathrm{~V}$ is chosen. The sensitivity is generally maximal in neutralized general $\mathrm{pH}$, depending on the analyte and the safranin capability to mediate the proton transfer.

Eosin dye (Figure 20) has also been frequently used in the dye polymer-based electroanalytical sets [89 - 92]. Paracetamol, folic acid [89], 2-4-dichlorophenol [90], hydroquinone and catechol [91] and VP-16 drug [92] are the most important analytes, detected by poly(eosin)-modified electrode.<smiles>NC(=O)c1ccccc1-c1c2cc([N+](=O)[O-])c(=O)c(Br)c-2oc2c(Br)c([N+](=O)[O-])c([N+](=O)[O-])cc12</smiles>

Figure 20. Eosin dye.

The eosin dye electropolymerization is usually carried out by $\mathrm{CV}$ in a potential range between $-1,2$ and $+1,0 \mathrm{~V}$ over carbon materials, and the electroanalytical cycle of eosin may be accompanied by ionic forms transformation. The $\mathrm{pH}$ chosen for the electrochemical analysis is dependent on which eosin form is polymerized and varies from moderately acidic to neutral.

Dianix blue dye (Figure 21) has been polymerized in order to quantify a great variety of analytes, including levodopa [93, 94], in the presence of ascorbic and uric acid without and with the possibility of simultaneous detection over GCE and MWCNT. The dianix blue dye 
polymerization has been carried out by $\mathrm{CV}$ between $-0,2$ to $1,8 \mathrm{~V}$. The presence of a quinonic fragment in the dye structure augments the oxidation potential but, at the same time, makes the proton transfer mediation much better. The polymerization is realized via aromatic moieties.<smiles>Nc1ccc(O)c2c1C(=O)c1c(N)cc(-c3ccc(O)cc3)c(O)c1C2=O</smiles>

Figure 21. Dianix blue dye.

Alizarin red dye (Figure 22) is another anthraquinone dye frequently used as a monomer for sensing conducting polymers [95 - 102]. It has already been used with analytes like omeprazole [95] on CPE, oxandrolone in urine on HOPG [96], metronidazole on GCE [97], hydrazine [98], dopamine [99], catechol [100], and serotonin [101]. Poly(alizarin) can also form metal complexes, used as catalysts for oxygen evolution [102].<smiles>O=C1c2ccccc2C(=O)c2c1cc(S(=O)(=O)O)c(O)c2O</smiles>

Figure 22. Alizarin red dye.

The alizarin red dye is frequently used because of its flexible electrochemical behavior, as the dye includes quinonic and hydroquinonic moieties at the same time, capable of receiving or donating protons, depending on pHand analyte composition. On the other hand, the presence of strong acceptor groups makes higher its electrooxidation potential. Thus alizarin red has to be polymerized by $\mathrm{CV}$ on $-0,6$ to $+1,4 \mathrm{~V}$.

Carmine dye (Figure 23) has also been used as a monomer for electroanalytical purposes $[103,104]$. It has been used for the determination of specific analytes like tinidazole [103] and 4-nitrophenol. Both accepting groups and steric conditions make difficult carmine polymerization. Nevertheless, it may be polymerized in potentiostatic mode using the anodic potential $+1,6 \mathrm{~V}$ in acidic media $\left(\mathrm{H}_{2} \mathrm{SO}_{4}\right)$.<smiles>Cc1c(C(=O)O)c(O)cc2c1C(=O)c1c(O)c(C3OC(CO)C(O)C(O)C3O)c(O)c(O)c1C2=O</smiles>

Figure 23. Carmine red dye. 
As for the electroanalytical properties are realized in flexible $\mathrm{pH}$ conditions, as, similarly to the alizarine red, as they possess both hydroquinonic and quinonic moieties.

Methylene blue (Figure 24) is one of the most used phenothiazine dyes in electroanalytic [105 - 108]. It has already been used for different analytes, including the polyphenolic compounds [105], OH-radicals and other radical scavengers [106], nitrite [107], 5-aminosalicylic acid [108], uric acid, and xanthine [109]. It has also been copolymerized with pyrrole [110] and other monomers for electroanalytical purposes. Its other use is in supercapacitors $[111,112]$. Its electropolymerization is given in similar conditions to those characteristic to the acridine orange and acridine red, but in a bit lower potential, due to the less accepting influence of the sulfur atom.<smiles>Cc1ccc2nc3ccc(N(C)C)cc3[s+]c2c1</smiles>

Figure 24. Methylene blue.

Azure A (Figure 25), a similar compound to methylene blue, has also been used for electroanalysis [113 - 115]. It's polymerized in similar conditions to methylene blue (CV from $-0,2$ to $1,3 \mathrm{~V}$ ) and may also be used in electrochromic appareils [115]. It has also been used as a catalyst for $\mathrm{H} 2 \mathrm{O} 2$ oxidation [116].<smiles>CN(C)c1ccc2nc3ccc(N)cc3[s+]c2c1</smiles>

Figure 25. Azure A dye.

The famous BODIPY (Figure 26) fused dyes have also been used as monomers for polymerization purposes in different areas, including electroanalytic [117]. They may also be used in copolymers as binding rings, augmenting the polymer conductivity and electroanalytical efficiency.<smiles></smiles>

Figure 26. BODIPY moiety.<smiles>CNc1ccc2nc3ccc(N(C)C)cc3[s+]c2c1</smiles>

Figure 27. Azure B dye.

Sometimes the dyes may copolymerize for electroanalytical purposes. For example, in [118], azure B dye (Figure 27) has been copolymerized with proflavine, yielding a doxorubicin 
sensing polymer. The polymerization has been given on a GCE with the potential scan between $-0,8$ and $+1,2 \mathrm{~V}$.

In certain cases, the metal dye complexes also polymerize or copolymerize for electroanalytical purposes. For example, in work [119], pyrrole was electropolymerized with a copper complex of Salabza dye (Figure 28) by CV in the range between $-0,2$ and 1,0 peak, yielding a polymer sensitive to catechol at micromolar quantities.

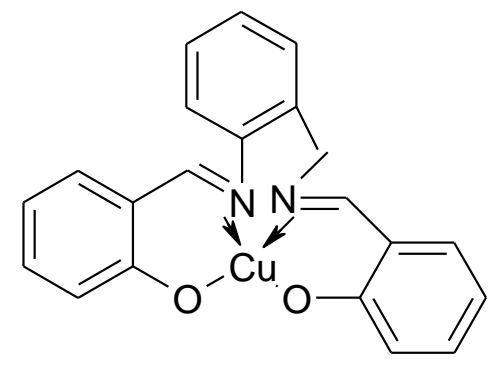

Figure 28. Salabza-Cu${ }^{2+}$ complex.

\section{Conclusions}

From the review, it is possible to conclude that the dyes are frequently used for electrochemical polymerization on carbon material electrodes. Generally, the dye electropolymerization is given by cyclic voltammetry, alternating the electrode polarity. The polymerization kinetics (cation-radical formation and interaction mechanism, number of $\mathrm{CV}$ cycles), like the resulting polymer's electroanalytical behavior, tend to be highly dependent on the background electrolyte composition, dye structure, and analyte chemical properties.

\section{Funding}

This research received no external funding.

\section{Acknowledgments}

This research has no acknowledgments.

\section{Conflicts of Interest}

The authors declare no conflict of interest.

\section{References}

1. Stejskal, J.; Kohl, M.; Trchová, M.; Kolská, Z.; Pekárek, M.; Křivka, I.; Prokeš, J. Conversion of conducting polypyrrole nanostructures to nitrogen-containing carbons and its impact on the adsorption of organic dye. Materials Advances 2021, 2, 706-717, https://doi.org/10.1039/D0MA00730G.

2. Gu, Y.; Qiao, Y.; Meng, Y.; Yu, M.; Zhang, B.; Li, J. One-step synthesis of well-dispersed polypyrrole copolymers under gamma-ray irradiation. Polymer Chemistry 2021, 12, 645-649, https://doi.org/10.1039/D0PY01566K.

3. Kaynak, A.; Zolfagharian, A.; Featherby, T.; Bodaghi, M.; Mahmud, M.A.P.; Kouzani, A.Z. Electrothermal Modeling and Analysis of Polypyrrole-Coated Wearable E-Textiles. Materials 2021, 14, https://doi.org/10.3390/ma14030550.

4. Zarei, M.; Samimi, A.; Khorram, M.; Abdi, M.M.; Golestaneh, S.I. Fabrication and characterization of conductive polypyrrole/chitosan/collagen electrospun nanofiber scaffold for tissue engineering application. International Journal of Biological Macromolecules 2021, 168, 175-186, https://doi.org/10.1016/j.ijbiomac.2020.12.031.

5. Samyn, L.M; Suresh Babu, R.;Devendiran, M.; de Barros, A.L.F. Electropolymerization of $p$ phenylenediamine films on carbon fiber fabrics electrode for flexible supercapacitors: surface and 
electrochemical characterizations. Ionics 2020, 26, 3041 - 3050, https://doi.org/10.1007/s11581-020-035620 .

6. Joshi, N.C.; Malik, S.; Gururani, P. Utilization of Polypyrrole/ZnO Nanocomposite in the Adsorptive Removal of $\mathrm{Cu}^{2+}, \mathrm{Pb}^{2+}$ and $\mathrm{Cd}^{2+}$ Ions from Wastewater. Letters in Applied NanoBioScience 2021, 10, 2339-2351, https://doi.org/10.33263/LIANBS103.23392351.

7. Yu, S; Piao, H; Sanoj Rejinold, $\mathrm{N}$ et al., Niclosamide-Clay Intercalate Coated with Nonionic Polymerfor Enhanced Bioavailability toward COVID-19 Treatment. Polymers 2021, 13, 1044, https://doi.org/10.3390/polym13071044.

8. Liu, X.; Liu, J. Biosensors and Sensors for Dopamine Detection. View 2021, 2, 20200102, https://doi.org/10.1002/VIW.20200102.

9. Sabbaghi, N.; Noroozifar, M.; Kerman, K. Nanocomposite of Ellagic Acid with Multi-Walled Carbon Nanotubes for the Simultaneous Voltammetric Detection of Six Biomolecules.C2021, 7, 43, https://doi.org/10.3390/c7020043.

10. Manjunatha, J. Poly(Adenine) Modified Graphene-Based Voltammetric Sensor for the Electrochemical Determination of Catechol, Hydroquinone and Resorcinol. The Open Chemical Engineering Journal 2020, 14, 52 - 62, https://doi.org/10.2174/1874123102014010052.

11. Ahmad, Kh.; Kumar, P.; Mobin, Sh. A Highly Sensitive and Selective Hydroquinone Sensor Based on a Newly Designed N-rGO/SrZrO 3 Composite. Nanoscale Adv. 2020, 2, 502, https://doi.org/10.1039/c9na00573k.

12. Romero-Montero, A.; del Valle, L.J.; Puiggali, J. et al. Poly(Gallic Acid)-Coated Polycaprolactone Inhibits Oxidative Stress in Epithelial Cells.Mat. Sci. Eng. C. 2020, 115, 111154, https://doi.org/10.1016/j.msec.2020.111154.

13. Zamudio-Cuevas, Y.; Andonegui-Elguera, M. Aparicio-Juarez, A. et al. The Enzymatic Poly(Gallic Acid) Reduces Pro-Inflammatory Cytokines in vitro, a Potential Application in Inflammatory Diseases.Inflammation 2020, 44,174-185, https://doi.org/10.1007/s10753-020-01319-5.

14. Jung, Y.; Singh, N.; Choi, K-Sh. Cathodic Deposition of Polypyrrole Enabling the One-Step Assembly of Metal-Polymer Hybrid Electrodes.Angew. Chem. Int. Ed., 2009, 121, $8481 \quad$ - 8484, https://doi.org/10.1002/ange.200903596.

15. Ziyatdinova, G.; Guss, E.; Morozova, Ye.et al. Simultaneous voltammetric determination of gallic and ellagic acids in cognac and brandy using electrode modified with functionalized SWNT and poly(pyrocatechol violet). Food Anal Meth., 2019, 12, 2250-2261, https://doi.org/10.1007/s12161-01901585-6.

16. Anh, T.T.N.; Thu, V.V.; Dang, H.-S. et al. Cerium Oxide/Polypyrrole Nanocomposite as the Matrix for Cholesterol Biosensor.Adv. Polym. Techn. 2021, 2021, 6627645, https://doi.org/10.1155/2021/6627645.

17. Upadhyay, J.; Das, T.M.; Borah, R. Electrochemical Performance Study of Polyaniline and Polypyrrole Based Flexible Electrodes.Int. J. Polym. Anal. Characteriz. 2021, 26, $354 \quad-\quad 363$, https://doi.org/10.1080/1023666X.2021.1891799.

18. da Silva Júnior, F.A.G.; Araújo Vieira, S; Botton, S.A. et al. Antibacterial Activity of Polypyrrole-Based Nanocomposites: a Mini-Review. Polímeros 2020, 30, https://doi.org/10.1590/0104-1428.08020.

19. Gopakumar, D. A.; Pai, R.A.; Pottathara, Y. B. et al. Flexible Papers Derived From Polypyrrole Deposited Cellulose Nanofibers for Enhanced Electromagnetic Interference Shielding in Gigahertz Frequencies.J. Appl. Polym. Sci. 2020, 138, 50262, https://doi.org/10.1002/app.50262.

20. Kutorglo, E.M.; Elashnikov, R.; Rimpelova, S et al. Polypyrrole-Based Nanorobots Powered by Light and Glucose for Pollutant Degradation in Water. ACS Appl. Mater. Interfaces 2021, 13, 16173 - 16181 , https://doi.org/10.1021acsami.0c20055.

21. Boubdallaoui, M.; Aouzal, Z.; El Guerraf et al. Influence of polythiophene overoxidation on its physicochemical properties and corrosion protection performances. Mater. Today Proc. 2020, 11, S69-S74, https://doi.org/10.1016/j.matpr.2020.06.067.

22. Oberhaus, F.V.; Frense, D. Fast, Simple and Gentle Method for Removal of Polythiophene and Other Conducting Films from Gold Electrodes. J. Electroanal. Chem. 2021, 895, 115466, https://doi.org/10.1016/j.jelechem.2021.115466.

23. Bednarczyk, K.; Kukulski, T.; Fryczkowski, R. et al. Effect of Polythiophene Content on Thermomechanical Properties of Electroconductive Composites. Molecules 2021, 26, 2476, https://doi.org/10.3390/molecules26092476.

24. Dong Y.; Yeung, K.W.; Tang, Ch.-Y et al. Development of Ionic Liquid-Based Electroactive Polymer Composites Using Nanotechnology.Nanotechnol. Rev. 2021, 10, 99 - 116, https://doi.org/10.1515/ntrev2021-0009. 
25. Xiao, X.; Yan, X.; Magner, E.; Ulstrup, J. Polymer Coating for Improved Redox-Polymer-Mediated Enzyme $\begin{array}{lllll}\text { Electrodes. A } & \text { Mini-Review.Electrochem. Commun. }\end{array}$ https://doi.org/10.1016/j.elecom.2021.106931.

26. Pinto Medeiros, M.F.X.; Leyva, M.E.; Alencar de Queiroz, A.A.; Maron, L.B. Electropolymerization of polyaniline nanowires on poly(2-hydroxyethyl methacrylate) coated Platinum electrode. Polímeros 2020, 30, e2020008, https://doi.org/10.1590/0104-1428.02020.

27. Bednarczyk, K.; Matysiak, W.; Tanski, T. et al. Effect of Polyaniline Content and Protonating Dopants on Electroconductive Composites. Sci. Rep. 2021, 11, 7481, https://doi.org/10.1038/s41598-021-86950-4.

28. Jamil, S.; Ahmad, Z.; Ali, M. et al. Synthesis and Characterization of Polyaniline/Nickel Oxide Composites for Fuel Additive and Dyes Reduction. Chem. Phys. Lett. 2021, 776, 138713, https://doi.org/10.1016/j.cplett.2021.138713.

29. Mocoiu, A-M.; Tudor, J.A.; Micioiu, O. C. Application of Polyaniline for Flexible Semiconductors. Coatings, 2021, 11, 49, https://doi.org/10.3390/coatings11010049.

30. Saracino, E.; Zuppolini, S.; Guarino, V. et al. Polyaniline Nano-Needles into Electrospun Bioactive Fibres Support In vitro Astrocyte Response.RSC Adv. 2021, $11, \quad 11347 \quad$ - 11355 , https://doi.org/10.1039/D1RA00596K.

31. Falletta, E.; Ferretti, A.; Mondini,S. et al. Size-Dependent Catalytic Effect of Magnetite Nanoparticles in the Synthesis of Tunable Magnetic Polyaniline Nanocomposites. Chem. Papers 2021, 91, https://doi.org/10.1007/s11696-021-01607-z.

32. Neupane, S.; Bhusal, S.; Subedi, V. et al. Preparation of an Amperometric Glucose Biosensor on PolyanilineCoated Graphite.J. Sensors 2021, 2021, 8832748, https://doi.org/10.1155/2021/8832748.

33. Feng, X.; Sun, Sh.; Cheng, Ge et al. Removal of Uranyl Ion from Wastewater by Magnetic Adsorption Material of Polyaniline Combined with $\mathrm{CuFe}_{2} \mathrm{O}_{4}$.Ads. Sci. Technol. 2021, 2021, 5584158, https://doi.org/10.1155/2021/5584158.

34. McDaniel, J.; Josowicz, M.; Janata, J. Cover Feature: Quantized Electrodes: Atomic Palladium and Gold in Polyaniline.ChemElectroChem. 2021, 8, 1696, https://doi.org/10.1002/celc.202100428.

35. Li, H.; Le, Sh.; LKi, Q.; Zhang, X. A new Chromium (III) Microelectrode Based on Self-Assembled Diethylenetriamminepentaacetic Acid-Poly(Fuchsin Basic) Modified Electrode. Electroanalysis 2009, 21, 831 - 836, https://doi.org/10.1002/elan.200804481.

36. Taei, M.; Hasanpour, F.; Tavakkoli, N.; Bahrameian, M. Electrochemical Characterization of Poly(Fuchsine Acid) Modified Glassy Carbon Electrode and its Application For Simultaneous Determination of Ascorbic Acid, Epinephrine and Uric Acid. J. Mol. Liq.2015, 211, 353 - 362.

37. Wan, Q.; Wang, X.; Wang, X., Yang, N. Poly(Malachite Green) film: Electrosynthesis, Characterization and Sensor Application. Polymer 2006, 22, 7684 - 7692, https://doi.org/10.1016/j.polymer.2006.09.002.

38. Turbale, M.; Moges, A.; Dawit, M.; Amare, M. Adsorptive Stripping Voltammetric Determination of Tetracycline in Pharmaceutical Capsule Formulation Using Poly(Malachite Green) Modified Glassy Carbon Electrode. Heliyon 2020, 6, e05782, https://doi.org/10.1016/j.heliyon.2020.e05782.

39. Xu, M.; Zhu, J. Su, H. et al. Electrochemical Determination of Methyl Parathion Using Poly(Malachite Green)/Graphene Nanosheets - Nafion Composite Film-Modified Glassy Carbon Electrode. J. Appl. Electrochem. 2012, 42, 509 - 516, https://doi.org/10.1007/s10800-012-0425-1.

40. Barsan, M.M.; Pifferi, V.; Falciola, L.; Brett, C.M.A. New CNT/poly(Brilliant Green) and CNT/poly(3,4Ethylenedioxythiophene) based Electrochemical Enzyme Biosensors. Anal. Chim. Acta. 2016, 927, 35 - 45, https://doi.org/10.1016/j.aca.2016.04.049.

41. Ghica, M.E.; Brett, Ch. M.A.; Poly(Brilliant Green) and Poly(Thionine) Modified Carbon Nanotube Coated Carbon Film Electrodes for Glucose and Uric Acid Biosensors. Talanta 2014, 130, 198 - 206, https://doi.org/10.1016/j.talanta.2014.06.068.

42. Pifferi, V.; Barsan, M.M.; Ghica, M.E. et al. Synthesis, Characterization and Influence of Poly(Brilliant Green) on the Performance of Different Electrode Architectures, Based on Carbon Nanotubes and Poly(3,4Ethylenedioxythiophene). Electrochim. Acta. 2013, $\quad 98, \quad 199 \quad-\quad 207$, https://doi.org/10.1016/j.electacta.2013.03.048.

43. Zhang, Y.; Zhuang, H.; Lu, H. Electrocatalytic Oxidation of Hydroquinone at Poly(Crystal-Violet) FilmModified Electrodfe and its Selective Determination in the Presence of $o$-Hydroquinone and $\mathrm{m}$ Hydroquinone.Anal. Lett. 2009, 42, 339 - 351, https://doi.org/10.1080/00032710802507885.

44. Ganesh, P.S.; Kumara Swamy, B.E.; Fayemi, O.E. et al. Poly(Crystal Violet) Modified Pencil Graphite Electrode Sensor For the Electroanalysis of Catechol In the Presence of Hydroquinone.Sens. Bio-Sens. Res. 2018, 20, 47 - 54, https://doi.org/10.1016/j.sbsr.2018.08.001.

45. Chauhan, R; Gill, A.A.S.; Nate, Z; Karpoormath, R. Highly Selective Electrochemical Detection of Ciprofloxacin Using Reduced Graphene Oxide/Poly(Phenol Red) Modified Glassy Carbon Electrode.J. Electroanal. Chem. 2020, 871, 114254, https://doi.org/10.1016/j.elechem.2020.114254.

46. Bagheri, A.; Hassani Marand, M. Voltammetric and Potentiometric Determination of $\mathrm{Cu}^{2+}$, using an Overoxidized Polypyrrole Based Electrochemical Sensor. Russ. J. Electrochem. 2020, 56, 453-461, https://doi.org/10.1134/S1023193520060026. 
47. Karabiberoglu, S.; Dursun, Z. Over-Oxidized Poly(Phenol Red) Film Modified Glassy Carbon Electrode for Anodic Stripping Voltammetric Determination of Ultra-Trace Antimony (III).Electroanalysis 2016, 29, 1069 - 1080, https://doi.org/10.1002/elan.201600629.

48. Yang, G; Qu, X; Shen, M et al. Electrochemical Behavior of Lead (II) at Poly(Phenol Red) Modified Glassy Carbon Electrode and its Trace Determination by Differential Pulse Anodic Stripping Voltammetry.Microchim. Acta. 2008, 160, 275 - 281, https://doi.org/10.1007/s00604-007-0881-1.

49. Ntrallou, K; Gika, H.; Tsochatzis, E. Analytical and Sample Preparation Techniques for the Determination of Food Colorants in Food Matrices. Foods 2020, 9, 58, https://doi.org/10.3390/foods9010058.

50. Ozak, S.S.; Y1lmaz, Y. Ultrasound Assisted Hydrophobic Deep-Eutectic Solvent Based Liquid-Liquid Microextraction of Sudan Dyes in Spice Samples. Spectrochim. Acta. 2020, 236, 118353, https://doi.org/10.1016/j.saa.2020.118353.

51. Tajik, S.; Beitollahi, H.; Garkani Nejad, F. et al. Electrochemical Sensing of Sudan I Using the Modified Graphite Screen-Printed Electrode. Int. J. Env. Anal. Chem. 2020, 100, https://doi.org/10.1080/03067319.2020.1738418.

52. Pietruk, K.; Piatkowska, M.; Olejnik, M. Electrochemical Reduction of Azo Dyes Mimicking Their Biotransformation To More Toxic Products. J. Vet. Res. 2019, 63, 44, https://doi.org/10.2478/jvetres-20190044.

53. Afanga, H.; Zazou, H.; Titchou, F.E. et al. Integrated Electrochemical Processes for Textile Industry Wastewater Treatment: System Performances and Sludge Settling Characteristics. Sust. Env. Res. 2020, 30, 2, https://doi.org/10.1186/s42834-019-0043-2.

54. Vinothkumar, V.; Sangili, A.; Chen, Sh.-M. Voltammetric Determination of Sudan I by Using $\mathrm{Bi}_{2} \mathrm{WO}_{6}$ Nanosheets Modified Glassy Carbon Electrode. Int. J. Electrochem. Sci. 2020, 15, 2414 - 2429, https://doi.org/10.20964/2020.03.08.

55. Heydari, M.; Ghoreishi, S.M.; Khoobi, A. Novel Electrochemical Procedure for Sensitive Determination of Sudan II Based on Nanostructured Modified Electrode and Multivariate Optimization. Measurement 2020, 142, 105 - 112, https://doi.org/j.measurement.2019.04.058.

56. Karaboduk, K.; Erdoğan, H. Voltammetric Determination of Sudan I in Food Samples Using Its Cu (II) Compound.Food Techn. Biotechn. 2018, 56, 573 - 580, https://doi.org/10.17113/ftb.56.04.18.5679.

57. Tajik, S.; Aflatoonian, M.R.; Shabanzade, R. et al. Amplified Electrochemical Sensor Employing ZnO CuO Nanoplates for Sensitive Analysis of Sudan I. Int. J. Env. Anal. Chem. 2020, 100, 109 - 120, https://doi.org/10.1080/03067319.2019.1631304.

58. Shah, A. A Novel Electrochemical Nanosensor for the Simultaneous Sensing of Two Toxic Food Dyes.ACS Omega 2020, 5, 6187 - 6193, https://doi.org/10.1021/acsomega.0c00354.

59. Zeng, L., Peng, L.; Wu, D.; Yang, B. Electrochemical Sensors for Food Safety, in Nutrition in Health and Disease - Our Challenges Now and Forthcoming Times, 2018, https://doi.org/10.5772/intechopen.82501.

60. Tajik, S.; Ooroji, Y.; Ghazanfari, Z. et al. Nanomaterials Modified Electrodes for Electrochemical Detection of Sudan I in Food.J. Food Measurement. Character. 2021, https://doi.org/10.1007/s11694-021-00955-1.

61. de Oliveira, R.W.S.; Barros Gomes, P.R.; Diniz Ribeiro, J. et al. Determinação Espectrofotométrica de Cobre (II) em Aguardente de Mandioca (Tiquira). Rev. Colomb. Cien. Quím. Farm. 2020, 49, 353 - 371, https://doi.org/10.15446/rcciquifa.v49n2.89507 (in Portuguese).

62. Tkach, V.V.; Kushnir, M.V.; de Oliveira et al. Theoretical Description for Copper (II) Electrochemical Determination and Retention on a 1 (2-pyridilazo)-2-naphthole-Modified Anode. Lett. Appl. NanoBioSci. 2021, 10, 2078-2084, https://doi.org/10.33263/LIANBS102.20782084.

63. Kuskur, Ch. M.; Kumara Swamy, B.E.; Shivakumar, K. et al. Poly(Sunset Yellow) Sensor for Dopamine: A $\begin{array}{lllllll}\text { Voltammetric Study. J. } & \text { Electroanal. } & \text { Chem. } & \text { 2019, } & 840, & 52 & -\end{array}$ https://doi.org/10.1016/j.jelectrochem.2019.03.031.

64. Akkapinyo, Ch.; Subannajui, K; Poo-Arporn, Y.; Poo-Arporn, R. P. Disposable Electrochemical Sensor for Food Colorants Detection by Reduced Graphene Oxide and Methionine Film Modified Screen Printed Carbon Electrode. Molecules 2021, 26, 2312, https://doi.org/10.3390/molecules26082312.

65. Ziyatdinova, G.; Guss, E.V.; Morozova, E.V. et al. An Electrode Based on Electropolymerized Sunset Yellow for the Simultaneous Voltammetric Determination of Chlorogenic and Ferulic Acids.J. Anal. Chem. 2021, 76, 371 - 380, https://doi.org/10.1134/S106934821030163.

66. Naik, T.S.S.K.; Mwaurah, M.M.; Kumara Swamy, B.E. Fabrication of Poly(Sudan III) Modified Carbon Paste Electrode Sensor for Dopamine: A Voltammetric Study.J. Electroanal. Chem. 2019, 834, 71 - 78 , https://doi.org/10.1016/j.elechem.2018.12.054.

67. Kuskur, Ch. M.; Kumara Swamy, B.E.; Jayadevappa, H; Shivakumar, K. Electropolymerized Congo Red Film Based Sensor for Dopamine: A Voltammetric Stury. Insights Anal. Chem. 2017, 3, 1, https://doi.org/10.21767/2470-9867.100020.

68. Kiranmai, S.; Reddy, V.M.Y.; Venu, M. et al. Determination of Terazosin by Using Poly(Congo Red) Modified Carbon Paste Electrode.Anal. Bioanal. Electrochem. 2017, $9 \quad 154 \quad-\quad 163$, https://www.sid.ir/en/journal/ViewPaper.aspx?id=660591. 
69. Giribabu, K.; Haldorai, Y.; Rethinasabapathy, M. et al. Glassy Carbon Electrode Modified with Poly(Methyl Orange) as an Electrochemical Platform for the Determination of 4-Nitrophenol at Nanomolar Levels. Curr. Appl. Phys. 2017, 17, 1114 - 1119, https://doi.org/10.1016/j.cap.2017.04.016.

70. Monnappa, A.B.; Manjunatha, J.G.G.; Bhatt, A.S.; Nagarajappa, H. Sensitive and Selective Electrochemical Detection of Vanillin at Graphene Based Poly(Methyl Orange) Modified Paste Electrode.J. Sci. Adv. Mat. Dev. 2021, https://doi.org/10.1016/j.jsamd.2021.05.002.

71. Chiwunze, T.E; V.N. Palakollu, Gill, A.A.S. et al. A Highly Dispersed Multi-Walled Carbon Nanotubes and Poly(Methyl Orange) Based Electrochemical Sensor for the Determination of an Anti-Malarial Drug Amodiaquine. Mat. Sci. Eng. C. 2018, 97, 285 - 292, https://doi.org/10.1016/j.msec.2018.12.018.

72. Li, X.; Xu, G.; Hu, R. Selective Determinatio of Dopamine and Uric Acid at Poly(Acid Red 176) Modified Glassy Carbon Electrode in the Presence of Ascorbic Acid. Int. J. Electrochem. Sci. 2013, 8, 1920 - 1927 , www.electrochemsci.org/list13.htm\#issue2.

73. Kuskur, C.M.; Kumara Swamy, B.E.; Jayadevappa, H. Poly(Evans Blue) Sensor for Catechol and Hydroquinone: A Voltammetric Study.J. Electroanal. Chem. 2019, 833, $512 \quad$ - 519, https://doi.org/10.1016/j.jelechem.2018.12.012.

74. Charinthra, M.M.; Manjunatha, J.G. Fabrication of Poly(Evans Blue) Modified Graphite Paste Electrode as an Electrochemical Sensor for Sensitive and Instant Riboflavin Detection. Mor. J. Chem. 2021, 9, 7 - 17, https://doi.org/10.48317/IMIST.PRSM/morjchem-v9i1.18239.

75. Shetti, N.P.; Ilager, D.; Malode, Sh. J. et al. Poly(Eriochrome Black T) Modified Electrode for Electrosensing of Methdilazine.Processing 2020, 120, 105261, https://doi.org/10.1016/j.mssp.2020.105261.

76. Edris, N.M.M.A.; Abdullah, J.; Kamaruzaman, S. et al. Electrochemical Reduced Graphene OxidePoly(Eriochrome Black T)/Gold Nanoparticles Modified Glassy Carbon Electrode for Simultaneous Determination of Ascorbic Acid, Dopamine and Uric Acid.Arab. J. Chem. 2018, 11, 1301 - 1312, https://doi.org/10.1016/j.arabjc.2018.09.002.

77. Isik, H.; Ozturk, G.; Agin, F.; Kul, D. Electroanalytical Analysis of Guaifenesin on Poly(Acridine Orange) Modified Glassy Carbon Electrode and its Determination in Pharmaceuticals and Serum Samples.Combin. Chem. High Thr. Screen. 2021, 24, 376 - 385, https://doi.org/10.2174/1386207323666200709170450.

78. Agin, F. Electrochemical Determination of Amoxicillin on a Poly(Acridine Orange) Modified Glassy Carbon Electrode.Anal. Lett. 2016, 49, 1366 - 1378, https://doi.org/10.1080/00032719.2015.1101602.

79. Sun, W.; Wang, Y.; Gong, Sh. et al.Application of Poly(Acridine orange) and Graphene Modified Carbon/Ionic Liquid Paste Electrode for the Sensitive Electrochemical Detection of Rutin.Electrochim. Acta. 2013, 109, 298 - 304, https://doi.org/10.1016/j.electacta.2013.07.124.

80. Zhang, Yu; Jing, G.; Wang, Y.; Yang, Zh. Determination of Dopamine in the Presence of Ascorbic Acid using Poly(Acridine Red) Modified Glassy Carbon Electrode. Sensors 2003, 3, 443 - 450 , https://doi.org/10.3390/s31000443.

81. Agin, F.; Ozturk, G.; Kul, D. Voltammetric Analysis of Ephedrine in Pharmaceutical Dosage Forms and Urine Using Poly(Nile Blue A) Modified Glassy Carbon Electrode. Combin. Chem. High Thr. Screen. 2021, 24, 366 - 375, https://doi.org/10.2174/1386207323666200727100231.

82. Chitravathi, S.; Munichandraiah, N. Voltammetric Determination of Paracetamol, Tramadol and Caffeine using Poly(Nile Blue) Modified Glassy Carbon Electrode.J. Electroanal. Chem. 2016, 764, 93 - 103 , https://doi.org/10.1016/j.elechem.2016.01.021.

83. Chakkarapani, L.D.; Sangilimuthu, S.N.; Arumugam, S. New Electrochemical Sensor for the Detection of Biological Analytes Using Poly(Amidoamine) Dendrimer and poly(Nile Blue)-modified Electrode.J. Electroanal. Chem. 2019, 855, 113486, https://doi.org/10.1016/j.jelechem.2019.113486.

84. Liu, X. Electrochemical Sensor for Determination of Parathion Based on Electropolymerization Poly(Safranine) Film Electrode. Int. J. Electrochem. 2011, 2011, https://doi.org/10.4061/2011/986494.

85. Niu, L.; Lian, K.; Kang, W.; Li, Sh. Characterization of Poly(Safranine T)-Modified Electrode and Application for Simultaneous Determination of Epinephrine and Uric Acid Coexisting with Ascorbic Acid. J. Braz Chem. Soc. 2011, 22, https://doi.org/10.1590/S0103-50532011000200003.

86. Liu, X-L. A Novel Sensor based on Electropolymerization Poly(Safranine) Film Electrode for Voltammetric Determination of 4-Nitrophenol. Bull. Kor. Chem. Soc. 2010, 31, $1182 \quad-\quad 1186$, https://doi.org/10.5012/bkcs.2010.31.5.1182.

87. Saritha, D.; Gupta, V.K.; Reddy, A.V. B. et al. Development of a Simple, Selective, Stable and Ultrasensitive Poly(Safranine/nano NiO) Modified Carbon Paste Electrode for Selective Detection of Rutin in Buckwheat and Green Tea Samples. Int. J. Electrochem. Sci 2019, 14, $10093 \quad$ - 10110, https://doi.org/10.20964/2019.11.48.

88. Guo, S; Zhu, Q.; Yang, B. et al.Determination of Caffeine Content in Tea Based on Poly(Safranine T) Electroactive Film Modified Electrode. Food Chem. 2011, 129, 1311 - 1314, https://doi.org/10.1016/j.foodchem.2011.05.095.

89. Kuskur, C.M.; Kumara Swamy, B.E.; Jayadevappa, H. Electrochemical Studies of Paracetamol and Folic Acid in the Presence of Epinephrine at Poly (Eosin) Modified Electrode. A. Voltammetric Study.J. Biosens. Bioelectron. 2017, 8, 1000244, https://doi.org/10.4172/2155-6210.1000244. 
90. Zhu, X.; Zhang, K.; Wang, Ch. et al. Quantitative Determination and Toxicity Evaluation of 2,4Dichlorophenol Using Poly(Eosin Y)/Hydroxylated Multi-Walled Carbon Nanotubes Modified Electrode. Sci Rep. 2016, 6, 38657, https://doi.org/10.1038/srep38657.

91. He, J.; Qiu, R.; Li, W. et al. A Voltammetric Sensor based omn Eosin Y Film Modified Glassy Carbon Electrode for Simultaneous Determination of Hydroquinone and Catechol. Anal. Meth. 2014, 16, $6494-$ 6503, https://doi.org/10.1039/C4AY00575A.

92. Al-Jawadi, E.A.M.; Majeed, M.I. Detection of Anticancer Drug by Electrochemical Sensors at Modified Electrode (MWCNT/Poly Eosin Y). Nanomed Res. J. 2021, 6, $50 \quad-\quad 59$, https://doi.org/10.22034/NMRJ.2021.01.006.

93. Hatefi, A.; Karimi, M.A.; Barani, A.Soleymanzadeh, M. Poly(Dianix Blue)/Multi-Walled Carbon Nanotube Modified Electrode for Detection of Levodopa in the Presence of High Concentrations of Ascorbic and Uric Acids.Acta Chim. Slov. 2017, 64, 193 - 201, https://doi.org/10.17344/acsi.2016.3097.

94. Hatefi, A.; Karimi, M.A.; Barani, A.Soleymanzadeh, M. Poly(Dianix Blue) Modified Glassy Carbon Electrode as an Electrochemical Sensor for Simultaneous Determination of Levodopa, Ascorbic and Uric Acids.Anal. Bioanal. Electrochem. 2017, 9, 295 - 311,https://sid.ir/en/journal/ViewPaper.aspx?ID=660626.

95. Mahanthesha, K.R; Kumara Swamy, B.E; Vasantakumar Psai, K. Poly(Alizarin) Modified Glassy Carbon Electrode for the Electrochemical Investigation of Omeprazole. A Voltammetric Study. Anal. Bioanal. Electrochem. 2014, 6, $234-244$.

96. De Oliveira Farias, E.A; Furtado, N.J.S; Lopes de Macêdo, I. Y. et al. Poly(Alizarin Red S) on Pyrolytic Graphite Electrodes as a New Multi-Electronic System for Sensing Oxandrolone in Urine.Biosens. Bioelectron. 2021, 185, 113234, https://doi.org/10.1016/j.bios.2021.113234.

97. Dawit, M.; Turbale, M.; Moges, A; Amare, M. Poly(Alizarin Red S) Modified Glassy Carbon Electrode for Square-Wave Adsorptive Stripping Voltammetric Determination of Metronidazole in Tablet Formulation. PlOs One 2020, 15, e244115, https://doi.org/10.1371/journal.pone.0244115.

98. Karakaya, S. Development of an Amperometric Hydrazine Sensor at a Disposable Poly(Alizarin Red S) Modified Pencil Graphite Electrode. Mon. Chem. 2019, 150, 1911 - 1920, https://doi.org/10.1007/s00706019-02513-4.

99. Reddaiah, K.; Reddy, T.M.; Ramana, D.K.V.; Rao, Y.S. Poly - Alizarin Red S/Multiwalled Carbon Nanotube Modified Glassy Carbon Electrode for the Boost Up of Electrocatalytic Activity Towards the Investigation of Dopamine and Simultaneous Resolution in the Presence of 5-HT: A Voltammetric Study. Mater. Sci. Eng. C. 2016, 62, 506 - 517, https://doi.org/10.1016/j.msec.2015.12.036.

100.Zhang, Q.; Pan, D.; Zhang, H. et al. Development of Poly(Alizarin Red S)/Ionic Liquid Film Modified Electrode for Voltammetric Determination of Catechol. Electrochim. Acta. 2014, 133, 23 - 29 , https://doi.org/10.1016/j.elecacta.2014.03.189.

101.Reddaiah, K.; Rao, K.S.V.K.; Reddy, T.M. Electrochemical Detection of Serotonin in Human Serum Sample and Simultaneous Resolution in Presence of Epinephrine.Anal. Bioanal. Electrochem. 2018, 10, 175 - 191 , https://sid.ir/en/journal/ViewPaper.aspx?id=660788.

102. Zheng, L.; He, Ch. Electrodeposition of Poly-NiFe-Alizarin Red S Complex for Effieicne Electrocatalytic Oxygen Evolution Reactions. J. Solid State Electrochem. 2019, 23, $2595 \quad$ - 2600, https://doi.org/10.1007/s10008-019-04354-x.

103.Wang, Ch.; Wang, F; Li, Ch. et al. Voltammetric Sensor for Tinidazole Based on Poly(Carmine) FilmModified Electrode and Its Application. Biomed. Anal. 2006, 41, $1396 \quad$ - 1400, https://doi.org/10.1016/j.jpba.2006.02.040.

104. Li, Ch. Construction of a Novel Sensor Based on Electropolymerization of Carmine for Voltammetric Determination of 4-Nitrophenol. J. Appl. Polym. Sci. 2007, 103, $3271 \quad-\quad 3277$, https://doi.org/10.1002/app.25489.

105. Yin, Ch.; Zhuang, Q.; Xiao, Q. et al. Electropolymerization of Poly(Methylene Blue) on Flower-Like NickelBased MOFs Used for Ratiometric Electrochemical Sensing of Total Polyphenolic Content in Chrysanthemum Tea. Anal. Meth. 2021, 13, 1154 - 1163, https://doi.org/10.1039/d1ay00028d.

106.Braun, W.A.; Horn, B.C.; Hoehne, L. et al. Poly(Methylene Blue) - Modified Electrode for Indirect Electrochemical Sensing of $\mathrm{OH}$ Radicals and Radical Scavengers. An. Acad. Bras. Ciênc. 2017, 89, https://doi.org/10.1590/0001-3765201720160833.

107. Koyun, O.; Sahin, Y. Voltammetric Determination of Nitrite with Gold Nanoparticles/Poly(Methylene Blue)Modified Pencil Graphite Electrode: Application in Food and Water Samples. Ionics 2018, 24, 3187 - 3197 , https://doi.org/10.1007/s11581-017-2429-7.

108.Hosu, O.; Barsan, M.; Sandulescu, R. et al. Hybrid Nanocomposite Platform, Based on Carbon Nanotubes and Poly(Methylene Blue) Redox Polymer Synthetized in Ethaline Deep Eutectic Solvent for Electrochemical Determination of 5-Aminosalicylic Acid. Sensors, 2021, 21, 1161, https://doi.org/10.3390/s21041161

109.Liu, G.; Ma, W.; Luo, Y. et al. Simultaneous Determination of Uric Acid and Xanthine Using a Poly(Methylene Blue) And Electrochemically Reduced Graphene Oxide Composite Film Modified Electrode. J. Anal. Meth. Chem. 2014, 2014, 984314, https://doi.org/10.1155/2014/984314. 
110.Samyn, L.M.; Suresh Babu, R.; Devendiran, M.; Ferreira de Barros, A.L. One-Step Electropolymerization of Methylene Blue Films on Highly Flexible Carbon Fiber Electrode as Supercapacitors. Micro and Nano Sys Lett. 2021, 9, 3, https://doi.org/10.1186/s40486-021-00130-7.

111. Roldán, S.; Ferreira, M.G.; Menéndez, R. et al. Supercapacitor Modified with Methylene Blue as Redox Active Electrolyte. Electrochim. Acta. 2012, 83, 241 - 246, https://doi.org/10.1016/j.elecacta.2012.08.026.

112.Pandey, I.; Bairagi, P.K.; Verma, N. Electrochemically Grown Polymethylene Blue Nanofilm on CopperCarbon Nanofiber Nanocomposite: An Electrochemical Sensor for Creatinine. Sens. Act. B. Chemical. 2018, 277, 562 - 570, https://doi.org/10.1016/j.snb.2018.09.036.

113. Chen, C.H.; Mu, Sh. Electrochemical Polymerization of Azure A And Properties of Poly(Azure A).J. Appl. Polymer Sci. 2003, 88, 1218 - 1224, https://doi.org/10.1002/app.11780.

114.Jiménez-Pérez, R.; González-Rodríguez, J.; González-Sánchez, M.I. et al. Highly Sensitive $\mathrm{H}_{2} \mathrm{O}_{2} \mathrm{Sensor}$ Based on Poly(Azure A)-Platinum Nanoparticles Deposited on Activated Screen Printed Carbon Electrodes.Sens. Act. B. Chem 2019, 298, 126878, https://doi.org/10.1016/j.snb.2019.126878.

115.Guillén, E; Agrisuelas, J. García-Jareño, J.E.; Vicente, F. Electrochromic Performances of Poly(Azure A) Films from Digital Video-Electrochemistry.J. Electrochem. Soc. 2020, 167, 106514, https://doi.org/10.1149/1945-7111/ab9e3b.

116. Agrisuelas, J.; González-Sánchez, M.I.; Gómez-Monedero, B.; Valero, E. A Comparative Study of Poly(Azure A) Film-Modified Disposable Electrodes for Electrocatalytic Oxidation of $\mathrm{H}_{2} \mathrm{O}_{2}$ : Effect of Doping Action. Polymers 2018, 10, 48, https://doi.org/10.3390/polym10010048.

117.Fan, Y.; Zhang, J. Hong, Zh. et al. Architectures and Applications of BODIPY-Based Conjugated Polymers.Polymers 2021, 13, 75, https://doi.org/10.3390/polym13010075.

118. Porfireva, A.; Vorobev, V.; Babkina, S.; Evtugyn, G. Electrochemical Sensor Based on Poly(Azure B)-DNA Composite For Doxorubicin Determination. Sensors 2019, 19, 2085, https://doi.org/10.3390/a19092085.

119. Yalcinkaya, S; Çakmak, D. Electrochemical Synthesis of Poly(pyrrole-co[Cu(salabza)]: Its Electrocatalytic Activity Towards the Oxidation of Catechol.Hacettepe J. Biol. Chem. 2016, 44, 425, https://doi.org/10.15671/HJBC.2016.123. 